\title{
Analysis of Hanting Hotel Service Marketing Strategy
}

\author{
Min Qian ${ }^{1, a .}$, Taixiang Ding ${ }^{1, b . *}$ \\ ${ }^{1}$ School of Economics and Management, Nanjing University of Science and Technology, Nanjing \\ 210094, China; \\ ${ }^{2}$ School of Economics and Management, Nanjing University of Science and Technology, Nanjing \\ 210094, China; \\ a1684356170@qq.com, b863294271@qq.com
}

\begin{abstract}
This study explores the service marketing of Hanting Hotel on the background of current tourism economy development. First of all, we analyze the market environment from the perspective of macro economy and industry competition. Secondly, we make use of the service marketing $7 p$ theory to put forward feasible suggestions for the future improvement of Hanting Hotel.
\end{abstract}

Key words: Hanting Hotel; service marketing; service marketing 7p theory

\section{Introduction}

According to the data released by China National Tourism Administration, the tourism industry's overall contribution to the national economy in 2016 has reached 11\%. Accommodation consumption often accounts for a large part of tourism consumption, making the national demand for hotel accommodation are both rapidly rising in quantity and quality. As one of the most famous budget hotel brands in China, Hanting Hotel has become a major choice for some travelers..

\section{Hanting hotel market environment analysis}

\subsection{Political environment}

At present, the domestic policy environment is constantly changing. The 13th Five-Year Plan for Economic and Social Development of the People's requires hotels to lead environmental protection, and all relevant development needs to move closer to the theme of environmental friendly. In the same period, various relevent enterprises also need to combine the "Opinions on Promoting the Reform and Development of Tourism" brought by the "One Belt and Road" national opening strategy and understand the direction of future development and reform of the industry.

\subsection{Economic environment}

According to the National Bureau of Statistics, overall tourism revenue in 2017 is expected to reach 832 billion yuan. Obviously, as the "global dividend" and "demographic dividend" have became more prominent in the domestic market, people's travel diversification and travel demand have increased so that domestic tourism is expected to continuely grow. The demand for rest space provided by hotels will be more regular access to people's daily lives. 


\subsection{Social and cultural environment}

In particularly ,with the improvement of citizen's diatheses and their economic strength, people gradually demand that enterprises provide more reliable services, and they also require enterprises to assume a wider range of social responsibilities. The increasing moral awareness of customers is crucial to the development of hotel group's image. It can be seen that the change of social and cultural environment plays an important role in enlightenment for the emphasis placed on the products and services of the Hanting Hotel.

\subsection{Technical Environment}

Especially in the hospitality industry, most hotels have already moved most of the service prefixes to the mobile screen through service intelligence, enabling customers to shop online in the user interface, pay a deposit, and ask for help. The operation of the data allows the hotel through the Internet background can understand the customer's booking cycle, habits of accommodation, requirements of room. The cloud-based management system through the information direct connection, member system, such as direct connection to the hotel quickly and easily to meet the needs of different clients.

\section{Industry competition analysis}

\subsection{Competitor's competitiveness}

Economy hotels have grown rapidly for two decades. Gaming among competitors in the same industry has become the focus of how to cut this market. Under this fiercely competitive Red Sea, mergers and withdrawals are always taking place. Therefore, it is crucial to pay attention to the strategic layout and trends of major competitors.

\subsection{Potential competitors' ability to enter}

Currently, the first tier brands have occupied more than three-quarters target market. These brands depending on years of management experience, many years of supply or distribution channels have kept the potential competitors. As a result, potential competitors have very little access to the market.

\subsection{Alternatives to alternative capabilities}

At present, the hotel industry can not be ignored object whitch is the short-term rental industry, because the short-term rental industry shows the booming development trend with more and more capital , and high subsidies to allow landlords to transfer higher customer value. The external effect and customer expectation formed by the short rental industry in residential hotels have also caused violent impact on economic hotels.

\subsection{Supplier bargaining power}

Conventional suppliers of Hanting Hotels are mainly real estate property suppliers, hotel supplies food ingredients suppliers, decoration materials suppliers. Therefore, when opening a new or new hotel business, enterprise need to select fitting-out companies, design companies, suppliers of hotel supplies and foodstuffs, etc, whitch can reduce costs and achieve light asset operations.

\subsection{Buyer's bargaining power}

As of now, travel brokers are the main customer of hotels. Ctrip, which occupies more than half of the market, belongs to the same founder as China Lodging Group Co., Ltd. Therefore, in terms of channels, Hanting Hotels enjoys the advantages that other budget hotel brands can not meet. At the same time, Hanting Hotels relying on up to 80 million Han court members also give Hanting Hotel bargaining power. 


\section{Hanting Hotel Services Marketing Strategy}

Although the development and layout of the current Hanting Hotel is still outstanding, it is necessary to better highlight the future development strategy and promote its own advantages by building a service marketing portfolio.

\subsection{Hanting Hotel product strategy}

After all, the limited service provided by economy hotels is restricted by the general living standards and costs of the society. Therefore, hotel adopting a relatively single strategy is an objective requirement of the market. Therefore, the further product strategy of Hanting Hotel needs to be further standardized towards single standardization and special differentiation. In terms of a single standardization, it is to provide service facilities with high frequency of family life and high cost threshold for the clients. Secondly, the hotel needs to further bias the publicity, try to focus the customer's attention to the core of simplified services.

\subsection{Hanting Hotel price strategy}

Usually the general budget hotel pricing process has two links, the first is the uniform price required by the standardized products and services in the geographical area, which can attract price-sensitive target groups, then meet some of the special requirements through simplified, differentiated products and services. In addition, the pricing strategy of Hanting Hotel also needs to consider the prestige factors on this basis. Hanting hotel necessary to have a higher corporate image by raising prices in the peer, and uses the brand spillover value to proactively improve customer experience value.

\subsection{Hanting Hotel channel strategy}

After the completion of the hotel, in the direct sales channel, the hotel needs to rely on the customer service staff to interact with customers in time to understand the customer's relevant information, so as to strengthen the customer relationship and strengthen the brand.

If we consider the indirect channels of Hanting Hotel, now Hanting hotel needs by virtue of the number of scale gradually dilute the impact of indirect channels on the hotel format, the use of the industry's forefront of technology, thus breaking the shackles to form a Hanting hotel as the core value of the network.

\subsection{Hanting Hotel promotion strategy}

Hanting Hotel promotions are necessary from both potential customers and loyal customers to consider. First, by co-branding product promotion exhibition column, and the provision of services such as hotels try to sleep experiential marketing activities.

Second, each hotel format and third-party platform should be with the Hanting Hotel "low-cost assurance activities" to enhance the loyalty of customers on the hotel's goodwill. In order to cooperate with the accurate promotion of the computing system, the third-party platform should been used to refer to the history and user image of the user, and helpe the Hanting Hotel to expand its loyal customer base.

\subsection{Hanting Hotel staff strategy}

Hanting Hotel staff attaches importance to staff reliability, communication skills, responsibility, attitude and behavior. Therefore, the Hanting Hotel needs a detailed staff training program and an authorization management system. It insists on building first-line staff into first-class service staffs so that they will provide their customers with safe, comfortable and satisfying services as their own responsibility. 


\subsection{Hanting Hotel physical display strategy}

In recent years, Hanting Hotel should actively participate in external industry conferences such as the International Conference on Hotel Development and Innovation and Summit Forum to grasp the outward appearance of Hanting Hotel.

Second, the Hanting Hotel should conduct more marketing activities, such as the hotel event information and introduction targeted to potential customers and loyal customers, so as to create a well-known hotel brand image.

\subsection{Hanting Hotel service process strategy}

For economy hotels, service management is based on streamlining the process. Therefore, even if all the service process details of Hanting Hotel can be handled through the front connection, in order to share staff pressure and save time for better problem solving services, it is necessary to provide mobile client intelligent consultation service, Intelligent booking room service, as well as online customer service complaint service, evaluation service.

\section{Conclusions}

This article proposed to the Hanting Hotel more refined suggestions for improvement, hope that the Hanting Hotel can continue in the new environment for marketing innovation. At the same time, I also hope that in the future, Hanting Hotels will continue to lead the domestic budget hotels towards the international market. However, small and medium-sized budget hotel brands can learn from the experience of Hanting to adopt their own service marketing strategies to enhance the overall industry standard.

\section{References}

[1] Chang H P, Ma C C. Managing the service brand value of the hotel industry in an emerging market.[J]. International Journal of Hospitality Management, 2015, 47:1-13.

[2] Ferrari S. Marketing strategies in the age of web 3.0[J]. Bmc Health Services Research, 2016, 5(1):20.

[3] Rodríguez T F E, Díaz M R. Make or buy in the hotel marketing department: transaction costs, financial and relational performance[J]. Tourism \& Management Studies, 2017, 13:págs. 7-17.

[4] Bo L. Research on Strategic Cost Control of Economy Hotels - From the Perspective of Value Chain [J] .Chinese Journal of Accounting, 2016 (2): 69-71.

[5] Hong W. Study on Themed Hotel Management Strategies of Economy Hotels [J]. Technology Economics and Management Research, 2014 (12): 71-74. 